\title{
PRODUÇÃO DE BIOTENSOATIVO UTILIZANDO Pseudomonas aeruginosa (P.A.) E RESÍDUO AGROINDUSTRIAL (MANIPUEIRA) COMO SUBSTRATO
}

\author{
M. S. Bezerra ${ }^{1,2}$, V. C. D. Holanda ${ }^{2}$, J. A. Amorim², G. R. Macedo ${ }^{1}$, E. S. Santos ${ }^{1}$ \\ ${ }^{1}$ Prog. de Pós-graduação em Eng. Química - Depto de Eng. Química- Universidade Federal do Rio Grande do Norte \\ ${ }^{2}$ Instituto Federal de Educação, Ciência e Tecnologia do Rio Grande do Norte. \\ marcio.bezerra@ifrn.edu.br
}

Artigo submetido em outubro/2011 e aceito em março/2012

\begin{abstract}
RESUMO
Biossurfactantes são moléculas anfotéricas que agem preferencialmente na interface de fluidos de diferentes polaridades como água e óleo, podendo ser sintetizados por micro-organismos. Utilizando um planejamento fatorial $2^{4-1}$ (fração meia), 10 ensaios foram realizados utilizando Pseudomonas aeruginosa (P.A.) AP029/GVII-A como micro-organismo, em incubador rotatório (shaker). Foi analisada a influência dos fatores (temperatura, agitação, razão de aeração e concentração do meio de cultivo) em dois diferentes níveis para a síntese do biossurfactante. Amostras foram coletadas durante todo o cultivo até completadas $132 \mathrm{~h}$ de fermentação. Buscou-se o melhor resultado
\end{abstract}

acompanhando a produção através do consumo de substrato, massa seca, redução da tensão superficial (método do anel) e índice de emulsificação. Os resultados mostraram que a manipueira é um substrato bastante assimilável na produção do biotensoativo, alcançando $91 \%$ de consumo pelo micro-organismo em estudo. A temperatura de cultivo revelou ser um dos fatores preponderantes na síntese do metabólito, acompanhada pela razão de aeração e também pela agitação. Os melhores resultados mostraram uma redução de $30 \%$ da tensão superficial (\%RTS) em relação ao meio, alcançando valores de $30 \mathrm{mN} / \mathrm{m} ; 3,0 \mathrm{~g} / \mathrm{L}$ de biomassa e índice de emulsificação superior a $65 \%$.

PALAVRAS-CHAVE: manipueira, Pseudomona aeruginosa, biossurfactante, cinética

\section{BIOTENSOATIVE PRODUCTION USING Pseudomonas aeruginosa (P.A.) AND AGROINDUSTRY WASTE (CASSAVA WASTEWATER) AS SUBSTRACT}

\begin{abstract}
Biosurfactants are amphoteric molecules that act preferentially on the interface of fluids of different polarities such as water and oil, and they may be synthesized by micro-organisms. Using a factorial design $2^{4-1}$ (half fraction) 10 assays were performed using Pseudomonas aeruginosa (PA) AP029/GVII-A as microorganism in rotary incubator (shaker), in which we analyzed the influence of factors (temperature, agitation, rate of aeration and concentration of culture medium) at two different levels for the synthesis of biosurfactant. Samples were collected throughout the cultivation until we completed $132 \mathrm{~h}$ of fermentation. We tried the best result following the production
\end{abstract}

through consumption of substrate, dry matter, reduction of surface tension (ring method) and emulsification index. The results showed that the cassava wastewater is a very assimilable substrate for the production of biosurfactant, reaching $91 \%$ of consumption by the micro-organism under study. The cultivation temperature was found to be one of the leading factors in the synthesis of the metabolite, followed by aeration rate and also due to the agitation. The best results showed a reduction of $30 \%$ in surface tension (\% RTS) for the medium, reaching values of 30 $\mathrm{mN} / \mathrm{m}, 3.0 \mathrm{~g} / \mathrm{L}$ of biomass and emulsification index greater than $65 \%$.

KEY-WORDS: cassava wastewater, Pseudomona aeruginosa, biosurfactant, kinetics. 


\section{PRODUÇÃO DE BIOTENSOATIVO UTILIZANDO Pseudomonas aeruginosa (P.A.) E RESÍDUO AGROINDUSTRIAL (MANIPUEIRA) COMO SUBSTRATO}

\section{INTRODUÇÃO}

Efluentes lançados ao meio ambiente trazem uma preocupação de bastante relevância para as indústrias, necessitando-se de um tratamento prévio para que atendam a legislação vigente antes de terem a sua disposição final. A manipueira é o efluente resultante da industrialização da mandioca, decorrente da prensagem da mandioca ralada e lavada no processo da obtenção da farinha (Costa et al., 2009), possuindo um alto teor de matéria orgânica e um glicosídio chamado linamarina que é facilmente hidrolisado a cianeto, composto altamente tóxico ao metabolismo, sendo na maioria das vezes descartada in natura nos cursos d'água acarretando um grande problema ambiental (Costa et al, 2009; Cordeiro, 2006). Apesar de altamente poluente, a manipueira pode ser empregada como matéria-prima para outros processos industriais, por apresentar altas concentrações de carboidratos, nitrogênio e sais minerais. Entre as alternativas, encontra-se a produção de biossurfactantes (Costa et al., 2009; Barros, Ponezi e Pastore, 2008; Nitschke e Pastore, 2006).

Surfactantes (SURFace ACTive AgenTS) é a denominação dada a compostos comumente presentes em sabões e detergentes. São moléculas anfipáticas, de superfície ativa, consistindo de dois domínios, um hidrofílico e outro hidrofóbico, onde o domínio hidrofóbico incide em um hidrocarboneto, enquanto que a parte hidrofílica pode ser não iônica, iônica (catiônica ou aniônica) ou anfotérica (Mohamed et al., 2010; Sabatini et al., 2006). Com base a essa natureza, os surfactantes podem atuar entre duas interfaces de fluidos de diferentes polaridades tais como óleo/água ou água/ar (Sekhon, Khanna e Cameotra, 2011; Banat et al., 2010). Os microorganismos sintetizam biossurfactantes para as seguintes funções: aumentar a biodisponibilidade de substratos hidrofóbicos (Das, Mukherjee e Sen, 2008; Calvo, Toledo e López, 2004); complexar metais pesados, reduzindo a sua toxicidade (Pacwa-Płociniczak et al.,2011; Das, Mukherjee e Sen, 2008; Sandrin et al., 2000); aumentar a atividade antimicrobiana (Saravanakumari e Mani, 2010); aumentar a patogenicidade e fixar ou desprender substratos (Gomes e Nitschke, 2012).

Os biossurfactantes são de grande relevância nas indústrias, como por exemplo, de alimentos (Nitschke e Costa, 2007), farmacêutica (Cohen et al., 2010), de petróleo, de produtos de higiene e de cosméticos (Lourith e Kanlayavattanakul, 2009), de mineração e na indústria agrícola (Banat et al, 2010; Fathabad, 2011). O uso do biotensoativo também se estende a aplicações ambientais, em tratamento de solo e água contaminados por hidrocarbonetos (Cameotra e Makkar, 2010). A utilização dos surfactantes naturais ainda é limitada pela competição com os surfactantes de origem sintética devido ao alto custo de produção, associado à baixa produtividade e ao uso de substratos caros. (Li et al, 2011; Makkar, Cameotra e Banat, 2011; Mukherjee, Das e Sen, 2006). As indústrias da área petrolífera requerem grandes quantidades de surfactantes, dessa forma, é fundamental que estes gastos sejam reduzidos, o que pode ser em parte obtido com o uso de matérias-primas de baixo custo, a exemplo de resíduos agroindustriais. 
Estes metabólitos produzidos a partir de substratos baratos, renováveis, através de processos economicamente viáveis e com alto rendimento, permitem diminuir os custos de produção para níveis competitivos em relação aos similares obtidos por via petroquímica e, ao mesmo tempo, reduzir os problemas ambientais relativos ao descarte e aos custos do tratamento (Kronemberger et al., 2007; Makkar e Cameotra, 2002). Contudo, os substratos alternativos para a produção de biossurfactantes apresentam dificuldades em sua padronização; empecilho que se deve às variações naturais de composição, bem como aos custos de transporte, armazenagem e tratamentos prévios necessários.

Quando comparados aos surfactantes sintéticos, os biotensoativos apresentam um desempenho superior em se tratando de situações extremas de temperatura e $\mathrm{pH}$, elevada concentração de salinidade, baixa toxicidade e principalmente por serem biodegradáveis (Bello, et al., 2012; Lovaglio, et al., 2011; Nitschke e Pastore, 2002).

Bactérias, do gênero Pseudomonas, são produtoras de biossurfactantes (ramnolipídios). Esse potencial apresentado tem sido bastante explorado para aplicação na MEOR (Microbial Enhanced Oil Recovery - Recuperação Melhorada do Óleo por Micro-organismo) e em outros setores da cadeia do petróleo devido às propriedades ativas de superfície e a estabilidade das emulsões obtidas com os metabólitos sintetizados por espécies desse gênero (Das e Mukherjee, 2005; Li et al., 2002).

O presente trabalho vem mostrar a potencialidade da manipueira para a produção de biossurfactante usando o micro-organismo Pseudomonas aeruginosa AP029/GVII-A, bem como, a capacidade do metabólito sintetizado em reduzir a tensão superficial do meio aquoso e de formar emulsões estáveis.

\section{MATERIAIS E MÉTODOS}

\section{- Micro-organismo}

Para os ensaios utilizou-se uma cepa de Pseudomonas aeruginosa AP029/GLVII-A, isolada de poço de petróleo do Canto do Amaro/Mossoró/RN. A cepa pertence à UFRN e está guardada na coleção de culturas do Departamento de Antibióticos da UFPE.

A cultura foi mantida em meio sólido inclinado em tubos de ensaio de $10 \mathrm{~mL}$ com Triptone Soya Broth (TSB), $25 \mathrm{~g} / \mathrm{L}$ e ágar bacteriológico, $(20 \mathrm{~g} / \mathrm{L})$. A renovação das células foi realizada por repique no meio e incubação à 36 드 durante 48 horas. Após a incubação a cepa foi mantida em geladeira a $4^{\circ} \mathrm{C}$.

\section{- Fonte de carbono}

Foi utilizado manipueira como fonte de carbono, coletada em uma fábrica de farinha (Casa de Farinha dos Anjos) localizada no município de Vera Cruz/RN, sendo armazenada em bombonas plásticas estéreis de 20L. O substrato foi levado imediatamente para a Universidade Federal do Rio Grande do Norte (UFRN), Laboratório de Engenharia de Alimentos, onde foi aquecida até a fervura para inativações das enzimas e micro-organismos fermentativos presentes, como também, para remoção do material sólido insolúvel. Após resfriamento em temperatura 
ambiente, a manipueira foi centrifugada a $3000 \mathrm{rpm}$ (2620 rcf) por 20 minutos (Marca SOLAB Modelo SL-701). O sobrenadante foi armazenado em fracos plásticos de 1,5L a -18으.

\section{- Pré-inóculo}

Para o pré-inóculo, foi utilizado um Meio Diluído com Adição de Sais (MDS) preparado da seguinte forma: o meio de manipueira foi diluído com água destilada na proporção (1:1), seguido de adição de $1,0 \mathrm{~mL}$ de solução de estoque de sais $(0,01 \mathrm{~g} / 100 \mathrm{~mL}$ de EDTA, $0,3 \mathrm{~g} / 100 \mathrm{~mL}$ de $\mathrm{MnSO}_{4} \cdot \mathrm{H}_{2} \mathrm{O}, 0,01 \mathrm{~g} / 100 \mathrm{~mL}$ de $\mathrm{FeSO}_{4} \cdot 7 \mathrm{H}_{2} \mathrm{O}, 0,01 \mathrm{~g} / 100 \mathrm{~mL}$ de $\mathrm{CaCl}_{2}, 0,01 \mathrm{~g} / 100 \mathrm{~mL}$ de $\mathrm{CoCl}_{2} \cdot 6 \mathrm{H}_{2} \mathrm{O}$ e $0,01 \mathrm{~g} / 100 \mathrm{~mL}$ de $\mathrm{ZnSO}_{4} \cdot 7 \mathrm{H}_{2} \mathrm{O}$ ).

Alíquotas de $100 \mathrm{~mL}$ do meio MDS foi distribuído em 3,0 frascos Erlenmeyers de $250 \mathrm{~mL}$ que foram lacrados com rodilhões de algodão e gaze. Os frascos foram levados à autoclave para esterilização $\left(131^{\circ} \mathrm{C}, 20 \mathrm{~min}, 1 \mathrm{kgf}\right)$. Após esfriamento em temperatura ambiente, os Erlenmeyers seguiram para a câmara de fluxo laminar em que 3,0 alçadas de células oriundas do meio de manutenção foram transferidas assepticamente para os frascos contendo o meio MDS. Os frascos foram colocados em incubador rotatório (Nova Técnica Modelo NT-714) a 35C, por 16h, sob agitação de 200rpm.

\section{- Cultivo}

Erlenmeyers com capacidade para $250 \mathrm{~mL}$, contendo uma quantidade variada ( $90 \mathrm{~mL}, 135$ $\mathrm{mL}, 180 \mathrm{~mL}$ ) do meio de cultura (MDS), foram lacrados, esterilizados a 131 으 por 15 minutos sendo, em seguida, submetidos à temperatura ambiente até atingir $40^{\circ} \mathrm{C}$. Na câmara de fluxo laminar, estes frascos foram inoculados com $10 \%$ v/v do pré-inóculo (MDS). Após a inoculação, os frascos foram levados ao incubador rotativo em diferentes condições, conforme matriz do planejamento fatorial, sendo estudadas as variáveis: agitação, temperatura, razão de aeração e meio de cultivo (manipueira).

Amostras foram retiradas em intervalos regulares, a cada 4 horas nas 12 primeiras horas de cultivo, passando a ser coletada a cada 12 horas até completadas $132 \mathrm{~h}$. Em seguida, foram centrifugadas a $16000 \mathrm{rpm}$ (14.464 rcf) para a retirada do sobrenadante. $\mathrm{O}$ caldo livre de células para cada ponto foi armazenado em coletores universais estéreis e congelado a -18 ㅇ C para análises posteriores. As análises realizadas foram: medida de $\mathrm{pH}$, concentração de substrato e variação da tensão superficial. Também foi avaliada para o caldo livre de células, a capacidade de formar emulsões estáveis (índice de emulsificação, $E_{24}$ ) por $24 \mathrm{~h}$ em querosene comercial.

\section{- Planejamento fatorial}

Um planejamento experimental de fração meia $2^{4-1}$, com repetição no ponto central (Barros Neto et al, 2003), foi utilizado para avaliar a influência dos fatores: velocidade de agitação (100 e $200 \mathrm{rpm}$ ), temperatura (30 e 40ㄷ), concentração de substrato (meio diluído e integral), e razão de aeração $(0,4$ e 0,8$)$. Essa última sendo definida como a razão entre o volume de meio de cultivo e o volume do frasco $\left(\mathrm{V}_{\mathrm{m}} / \mathrm{V}_{\mathrm{f}}\right)$. A Tabela 1 apresenta os fatores com os níveis estudados. 
Tabela 1- Fatores e níveis para o planejamento fatorial $2^{4-1}$ com duplicata no ponto central

\begin{tabular}{|c|c|c|c|}
\hline \multirow{2}{*}{ VARIÁVEIS } & \multicolumn{3}{|c|}{ NíVEIS } \\
\cline { 2 - 4 } & $\mathbf{( - 1 )}$ & $\mathbf{( 0 )}$ & $\mathbf{( 1 )}$ \\
\hline Agitação (rpm) & 100 & 150 & 200 \\
\hline Temperatura (oC) & 30 & 35 & 40 \\
\hline Razão de Aeração & $0,4(100 \mathrm{ml})$ & 0,6 & $0,8(200 \mathrm{ml})$ \\
\hline Meio de Cultivo & $50 \%$ & $75 \%$ & $100 \%$ \\
\hline
\end{tabular}

Na Tabela 2 é apresentada a matriz dos ensaios realizados para esse trabalho. Os ensaios foram realizados obedecendo à aleatoriedade (Barros Neto et al, 2003).

Tabela 2 - Matriz do planejamento fatorial $2^{4-1}$ com duplicata no ponto central.

\begin{tabular}{|c|c|c|c|c|}
\hline Ensaio & $\mathbf{1}$ & $\mathbf{2}$ & $\mathbf{3}$ & $\mathbf{4}$ \\
\hline $\mathbf{1}$ & - & - & - & - \\
\hline $\mathbf{2}$ & + & - & - & + \\
\hline $\mathbf{3}$ & - & + & - & + \\
\hline $\mathbf{4}$ & + & + & - & - \\
\hline $\mathbf{5}$ & - & - & + & + \\
\hline $\mathbf{6}$ & + & - & + & - \\
\hline $\mathbf{7}$ & - & + & + & + \\
\hline $\mathbf{8}$ & + & + & + & 0 \\
\hline $\mathbf{9}$ & 0 & 0 & 0 & 0 \\
\hline 10 & 0 & 0 & 0 & \\
\hline
\end{tabular}

A análise do planejamento foi efetuada com o auxílio do programa Statistica 7.0.

\section{ANÁLISES}

\section{- Determinação da concentração celular}

O método utilizado para quantificar a concentração celular foi o de massa seca (ou peso seco). Este método consiste em separar as células do meio, secá-las e pesá-las (Bezerra 2006, Lobato, 2003). As amostras retiradas do shaker foram centrifugadas em tubos Eppendorfs de 2,0 $\mathrm{mL}$ a 16.464g (Nova Ténica - NT800) por 10 minutos. Os tubos Eppendorfs vazios foram previamente colocados em estufa (BIOPAR) a $70^{\circ} \mathrm{C}$ por $24 \mathrm{~h}$ até obter peso constante.

Após a centrifugação, o sobrenadante foi recolhido para outras análises. Nos tubos com a massa úmida foram adicionados $2,0 \mathrm{~mL}$ de água destilada para a lavagem e retirada de outros componentes solúveis ainda presentes. Terminada a segunda lavagem, as amostras foram colocadas na estufa a $70^{\circ} \mathrm{C}$ por 24 horas. Em seguida, os Eppendorfs eram colocados em dessecadores por 5 minutos e pesados. Cada ponto foi realizado em duplicata e o valor médio obtido foi considerado para os cálculos. A quantidade de biomassa ( $\mathrm{g} / \mathrm{L}$ ) foi calculada pela equação (1):

$$
m_{\text {seca }}=\frac{\left(T_{1}-T_{2}\right)}{2} \times 1000
$$


Sendo:

$\mathrm{T}_{1}=$ Tubo com biomassa

$\mathrm{T}_{2}=$ Tubo vazio

\section{- Determinação da concentração de substrato}

Na determinação da concentração de substrato utilizou-se o método do DNS. O método do DNS baseia-se na redução do ácido 3,5 dinitro-salicílico a ácido 3-amino-5- nitrosalicílico, ao mesmo tempo em que o grupo aldeído do açúcar é oxidado a grupo carboxílico com o desenvolvimento de coloração avermelhada, medida espectofotometricamente em $600 \mathrm{~nm}$. 0 procedimento utilizado é uma modificação do original de Miller (1959), uma vez que as amostras contêm amido (glicose+glicose) enquanto o método determina glicose + frutose. Por este motivo, é necessário realizar uma hidrólise prévia.

Em um balão volumétrico de $50 \mathrm{~mL}$, adicionou-se $1,0 \mathrm{~mL}$ da amostra, $0,5 \mathrm{~mL}$ de $\mathrm{HCl}$ e 6,0 $\mathrm{mL}$ de água. A solução foi então aquecida a 70 ㅇ $\mathrm{C}$ por 10 minutos, esfriada com água corrente e neutralizada com solução de $\mathrm{NaOH} 4,0 \mathrm{~N}$, utilizando-se 2 gotas de fenolftaleína como indicador. $\mathrm{O}$ balão foi completado com água destilada. Após a hidrólise, tomou-se $0,5 \mathrm{~mL}$ desta amostra; 2,5 $\mathrm{mL}$ do reagente DNS foram adicionados e os tubos levados para o banho termostático à 100 ㅇ C por 10 minutos. Em seguida, os tubos de ensaio foram deixados em água gelada por 3-5 minutos. Na sequência, 3,0 $\mathrm{mL}$ de água destilada foi adicionada, a solução foi agitada em vórtex e a absorbância a $600 \mathrm{~nm}$ foi medida. Utilizou-se como branco uma amostra com $0,5 \mathrm{~mL}$ de água destilada no lugar de $0,5 \mathrm{~mL}$ da amostra hidrolisada.

Uma curva de calibração foi construída, correlacionando a concentração de glicose com a leitura da absorbância a 600nm.

\section{- Determinação da tensão superficial}

A medida da tensão superficial é uma ferramenta comum e um método indireto para monitorar a produção de biossurfactantes. À medida que o micro-organismo cresce, ele sintetiza o biossurfactante e este metabólito é lançado ao caldo, reduzindo a tensão superficial.

A tensão superficial foi medida no tensiômetro modelo Kruss (K-6, Alemanha), que utiliza o método do anel (Du Noüy). As análises foram realizadas com o sobrenadante obtido após a centrifugação da amostra bruta, a uma temperatura de aproximadamente 25 ㄷ․ A cada início das análises, o anel foi esterilizado em bico de Bunsen e calibrado verificando a tensão superficial da água destilada, cujo valor é de aproximadamente $72,8 \mathrm{mN} / \mathrm{m}$.

Foram realizadas três medidas da tensão superficial para cada ponto em estudo, sendo considerada a média aritmética dos resultados.

\section{- Determinação do índice de emulsificação}

A capacidade dos biossurfactantes, para emulsificar hidrocarbonetos, foi avaliada pelo índice de emulsificação do sobrenadante da amostra final do processo fermentativo. Este índice foi determinado de acordo com o método de Wei, Chou e Chang, (2005). Neste caso, 2,0 mL do 
sobrenadante foi adicionado em um tubo contendo $2,0 \mathrm{~mL}$ de querosene comercial. A mistura foi agitada em vórtex por 2 minutos e permaneceu em repouso por 24 horas. 0 índice de emulsificação foi calculado conforme a equação (2)

$$
E_{24}=\frac{H_{\text {emulsão }}}{H_{t}} \times 100
$$

\section{Sendo:}

$\mathrm{E}_{24}=$ índice de emulsificação após 24h (\%),

$\mathrm{H}_{\text {emulsão }}=$ Altura da emulsão

$\mathrm{H}_{\mathrm{t}}=$ Altura total

\section{- Estudo cinético da síntese do biossurfactante}

O estudo cinético possibilita uma comparação entre diferentes formas de cultivo e permite estimar a melhor condição de cultivo (Schmidell, Lima e Aquarone, 2001).

Os rendimentos são valores obtidos através do estudo do crescimento microbiano e da produção de metabólitos, com estes resultados tem-se base para obter o fator de conversão de substrato-microrganismo. Dessa forma, pode-se definir $Y_{x / s}$ como o coeficiente global de conversão de substrato em células, também conhecido como coeficiente de rendimento aparente ou observado (equação 3).

$$
Y_{X / S}=-\frac{d X}{d S}
$$

Onde X é a concentração da biomassa e S representa a concentração do substrato.

O valor desse parâmetro varia ao longo de um cultivo, alcançando o valor máximo durante a etapa de crescimento exponencial em cultivos descontínuos.

A concentração celular varia durante um processo descontínuo, aumentando normalmente. Geralmente, as células constituem o "catalisador" das reações microbianas, onde o aumento da concentração celular ocasiona também uma variação das taxas.

Assim, resultados mais precisos são obtidos ao analisar as velocidades instantâneas em relação à concentração celular $(X)$. Logo, torna-se necessária a definição das velocidades específicas de crescimento celular ( \u ॠonforme a equação (4), essa equação foi definida por Gaden (Gaden, 1955 citado por Schmidell e Lima, 2007):

$$
\mu=\frac{1}{X} \frac{d X}{d t}
$$

\section{RESULTADOS E DISCUSSÃO}

Foram realizados 10 ensaios em shaker, explorando as seguintes condições: agitação (100, 150 e 200 rpm), temperatura (30, 35 e 40C), razão de aeração $(0,4,0,6$ e 0,8) e concentração de 
meio de cultura (diluído 50\% em água destilada, diluído $25 \%$ e integral) com o objetivo de avaliar a influência destas diferentes condições na produção de biossurfactante.

A Tabela 3 apresenta um resumo dos resultados das 10 cinéticas realizadas

Tabela 3 - Resultados para os ensaios realizados

\begin{tabular}{|c|c|c|c|c|c|c|c|}
\hline Ensaio & $\begin{array}{c}\text { Conc. } \\
\text { Cel. } \\
(\mathbf{g} / \mathbf{L})\end{array}$ & $\mathbf{Y}_{\mathbf{x} / \mathbf{s}}$ & $\begin{array}{c}\boldsymbol{\mu}_{\text {Xmáx }} \\
\left.\mathbf{( h}^{-1}\right)\end{array}$ & $\begin{array}{c}\text { Red. da } \\
\text { Tensão } \\
\text { Sup. }(\mathbf{\%})\end{array}$ & $\begin{array}{c}\mathbf{T S}_{\text {min }} \mathbf{t} \\
(\mathbf{m N} / \mathbf{m})\end{array}$ & $\mathbf{t}(\mathbf{h})$ & $\mathbf{E}_{24} \%$ \\
\hline 1 & 2,20 & 0,0874 & 0,07802 & 31,03 & $33,24( \pm 0,3)$ & 120 & 66,00 \\
\hline 2 & 2,00 & 0,0599 & 0,08708 & 28,96 & $33,78( \pm 0,3)$ & 108 & 60,00 \\
\hline 3 & 2,25 & 0,2596 & 0,06380 & 18,14 & $38,37( \pm 0,3)$ & 84 & 55,60 \\
\hline 4 & 3,00 & 0,1297 & 0,04128 & 04,65 & $40,89( \pm 0,3)$ & 72 & 65,38 \\
\hline 5 & 2,25 & 0,1780 & 0,02548 & 22,31 & $33,12( \pm 0,3)$ & 36 & 68,97 \\
\hline 6 & 2,50 & 0,1231 & 0,03628 & 30,08 & $30,92( \pm 0,3)$ & 48 & 62,96 \\
\hline 7 & 1,75 & 0,1259 & 0,04025 & 06,28 & $36,40( \pm 0,3)$ & 108 & 50,00 \\
\hline 8 & 2,00 & 0,1120 & 0,24324 & 06,23 & $43,36( \pm 0,3)$ & 120 & 60,00 \\
\hline 9 & 1,75 & 0,1174 & 0,06995 & 25,75 & $36,40( \pm 0,3)$ & 48 & 66,00 \\
\hline 10 & 2,00 & 0,1369 & 0,02192 & 25,50 & $36,40( \pm 0,3)$ & 72 & 65,38 \\
\hline
\end{tabular}

Utilizando o programa Statistica 7.0, o Diagrama de Pareto (Figura 1) mostra os contrastes significativos sobre síntese do biossurfactantes e as interações entre os fatores.

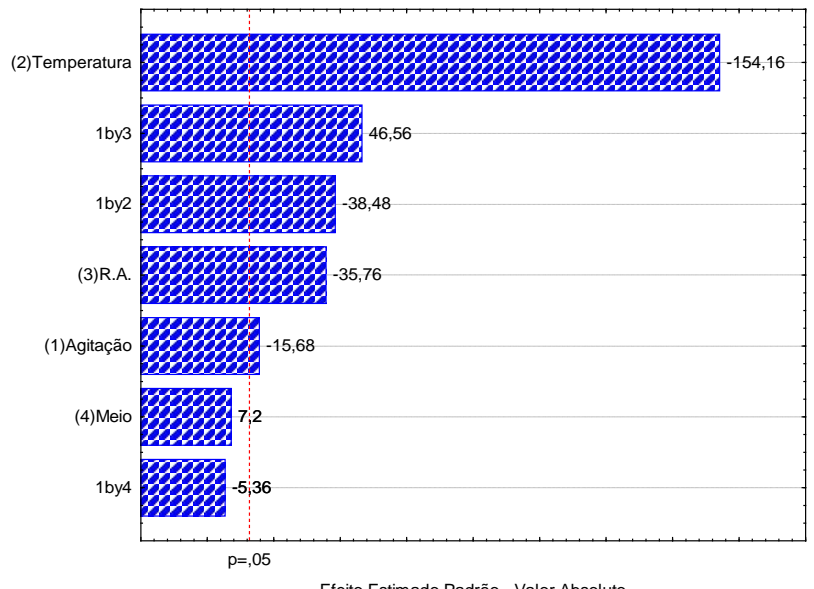

Efeito Estimado Padrão - Valor Absoluto

Figura 1 - Diagrama de Pareto para estimativa dos efeitos sobre a redução da tensão superficial

O efeito negativo provocado pelo contraste temperatura mostra que quanto menor a temperatura $\left(30^{\circ} \mathrm{C}\right)$, maior será a influência na síntese do metabólito em estudo. Fatores como razão de aeração e agitação também se mostraram significativos para os valores nos níveis inferiores em estudo, 0,4 e 100 rpm, respectivamente. Ainda, as interações entre agitação e razão de aeração e agitação e temperatura também contribuíram para a redução da tensão superficial. 
O único fator em estudo não significativo foi o meio manipueira, onde sua composição na forma diluída (50\%) ou na modalidade integral, não influenciou na porcentagem da redução superficial.

Batista et al. (2006) estudou diferentes cepas isoladas do solo e da água do mar na síntese de biossurfactante e de bioemulsificantes. Ao elevar a temperatura de 25ㄷ para 35으 verificaram que a temperatura não influenciava ou influenciava muito pouco na síntese dos metabólitos. A temperatura também não foi fator preponderante na síntese de ramnolipídios por Pseudomonas aeruginosa selvagem para Wei e colaboradores (2005), todavia, a temperatura ótima de produção esteve entre 30 e $37^{\circ} \mathrm{C}$. A síntese decresceu quando a temperatura atingiu a marca de $42^{\circ} \mathrm{C}$, esse resultado confirma com os dados obtidos para esse trabalho, em que a temperatura ótima de produção se apresentou entre $30^{\circ} \mathrm{C}$ (ensaios $1,2,5$ e 6) e 35ㅇ C (ensaios 9 e 10) e que os demais ensaios a 40 ํ C não apresentaram elevados índices de redução de tensão superficial.

Os resultados apontam uma tensão superficial média por volta de $33 \mathrm{mN} / \mathrm{m}$ para os melhores ensaios, atingindo valor mínimo de 30,92 $( \pm 0,3) \mathrm{mN} / \mathrm{m}(30,08 \%$ de redução da tensão superficial) para o ensaio 6 em apenas $48 \mathrm{~h}$ de cultivo. Haba et al (2000) ao produzir ramnolipídios por Pseudomonas aeruginosa em diferentes fontes de carbono (óleos), obteve redução de tensão superficial que variou de $32 \mathrm{mN} / \mathrm{m}$ a $36 \mathrm{mN} / \mathrm{m}$. Wei, Chou e Chang (2005) utilizando outra espécie, Pseudomonas aeruginosa $\mathrm{J} 4$ e efluente da indústria petroquímica obteve tensão superficial superior aos $31 \mathrm{mN} / \mathrm{m}$. Raza et al (2007) avaliou diversas fontes de carbono para a síntese do biossurfactante, utilizando Pseudomonas putida e obteve tensões superficiais margeando $35 \mathrm{mN} / \mathrm{m}$ após 7 dias de cultivo. Estudos realizados por Nitschke e Pastore (2006) utilizando manipueira como substrato e Bacillus subtilis na síntese do biossurfactante (surfactina) obteve uma redução da tensão superficial de $37 \%$ em relação ao ponto inicial, alcançando índices abaixo de $30 \mathrm{mN} / \mathrm{m}$.

As curvas representativas da cinética do crescimento para os ensaios 1, 2, 5 e 6, cujo possuem maiores resultados significativos estão ilustradas na Figura 2 abaixo.

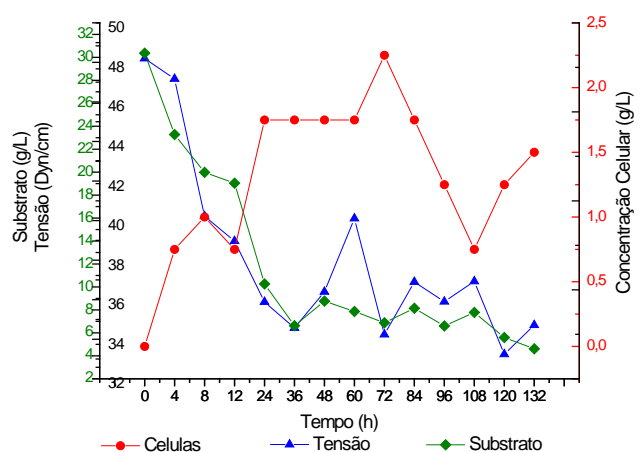

(1)

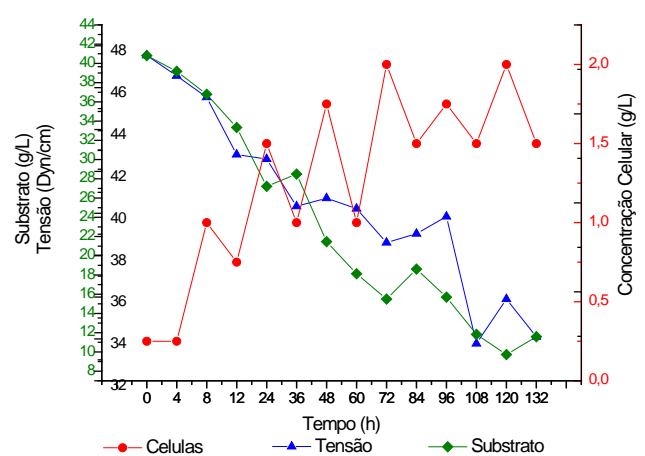

(2) 


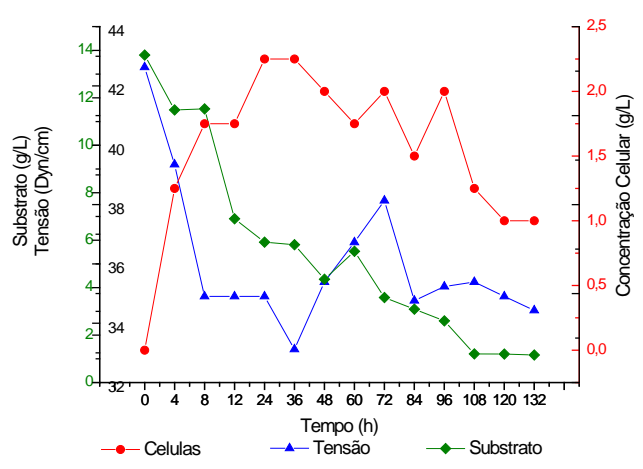

(5)

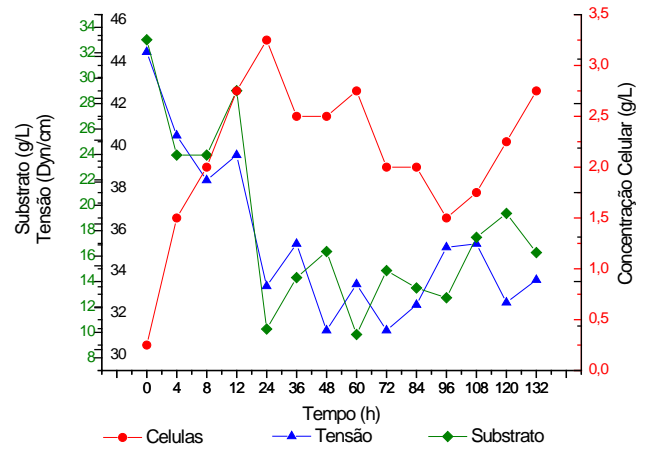

(6)

Figura 2 - Curvas de crescimento celular, consumo de substrato, variação da tensão superficial para os ensaios 1, 2, 5 e 6

Quando comparadas as condições de cultivos dos ensaios 1 e 2 com os ensaios 5 e 6, o fator de conversão de substrato em células $\left(\mathrm{Y}_{\mathrm{x} / \mathrm{s}}\right)$ apresentou maior para os ensaios 5 e 6 , mostrando que nessas condições de cultivos, o substrato é mais facilmente assimilável, aumentando-se o número de células e consequentemente a produção do metabólito no meio.

Através da Figura 2 (1), (5) e (6), nota-se que o crescimento microbiano ocorre até $24 \mathrm{~h}$ de cultivo e que a redução da tensão superficial também acompanha esse aumento da biomassa. Esses resultados mostram que a síntese do metabólito está associada, como também parcialmente associada ao crescimento celular, pois o micro-organismo ao entrar na fase estacionária, tempo de 24h, ainda não atingiu a Concentração Micelar Crítica (CMC). Nota-se que a tensão superficial continua a ser reduzida por mais $12 \mathrm{~h}$, alcançando o tempo de $36 \mathrm{~h}$.

A Figura 3 apresenta a superfície de resposta para a interação temperatura e agitação. Observa-se que ao reduzir a temperatura, fator de maior influência na síntese do metabólito, maior será a porcentagem da redução da tensão superficial, independente da agitação ocorrer em 100 ou 200 rpm.

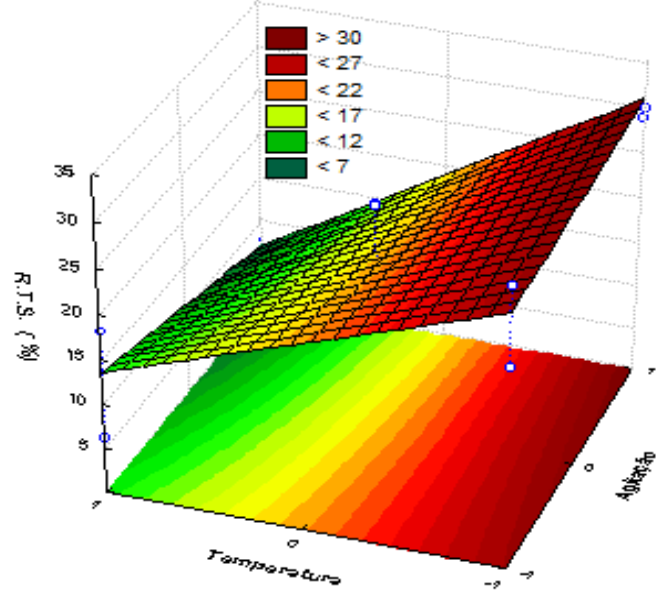

HOLOS, Ano 28, Vol 1 
Figura 3 - Superfície de resposta da redução da tensão superficial (\%RTS) em função da temperatura e da razão de aeração

A Figura 4 mostra o efeito entre a temperatura e a razão de aeração, ratificando o fator temperatura como efeito preponderante na síntese do metabólito. Todavia, havendo um pequeno acréscimo na porcentagem da redução da tensão superficial quando a razão de aeração passa a ser 0,4 .

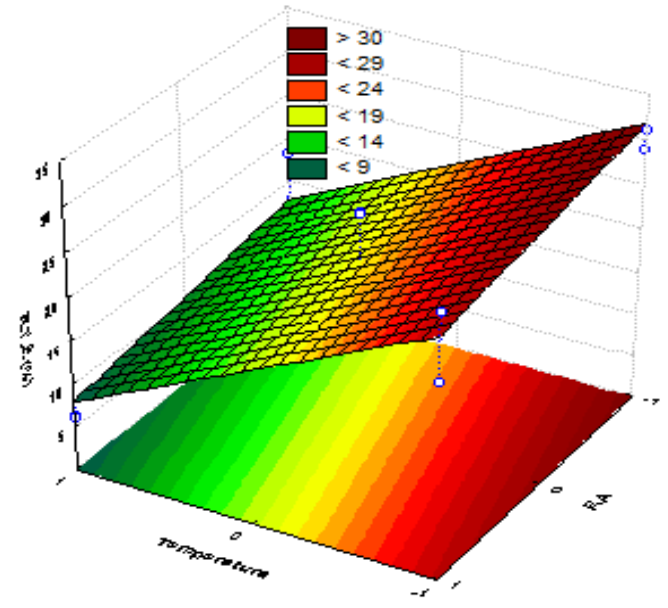

Figura 4 - Superfície de resposta da redução da tensão superficial (\%RTS) em função da temperatura e da razão de aeração

Os ensaios desse estudo apresentaram também um excelente poder de emulsificação, variando de 50 a $68 \%$ para as 24 primeiras horas, ainda acompanhando este índice, muitos deles permaneceram estáveis por $72 \mathrm{~h}$ ou mais. Benincasa et al (2004) utilizando Pseudomonas aeruginosa LB1 em meio mineral produziu um bioemulsificante. $\mathrm{O}$ valor de $50 \%$ para o $\mathrm{E}_{24}$ foi considerado satisfatório para o querosene. Assim como Benincasa, Batista et al. (2006) e Bicca et al (1999) também obtiveram valores de 50\% para o índice de emulsificação para o querosene comercial. Testes de emulsificação realizados por Haba et al (2000) apresentaram índice de emulsificação variando de 12 a 64\% para o metabólito sintetizado por diversos tipos de Pseudomonas. Costa, Nitschke e Contiero (2008) obtiveram rendimentos acima de $90 \%$ de emulsificação para o gênero Pseudomonas.

\section{CONCLUSÃO}

O planejamento experimental $2^{4-1}$ foi aplicado para os seguintes fatores, agitação, temperatura, razão de aeração e meio de cultura. Os mais significativos, em ordem, foram à temperatura, razão de aeração e agitação, obtendo a porcentagem de redução da tensão superficial como resposta. Ainda, de acordo com os dados obtidos, a combinação dos fatores (temperatura, razão de aeração e agitação) quando trabalhado nos menores níveis (30ㄷ; 0,4 ; 100rpm) mostraram ser as melhores condições de cultivo para a síntese do metabólito em estudo.

Os resultados também apresentaram a potencialidade da manipueira para ser utilizada como matéria-prima na síntese do biotensoativo, ocasionando uma redução de tensão superficial para valores próximos de $30 \mathrm{mN} / \mathrm{m}$ e índice de emulsificação de $68 \%$, tornando bastante significativos quando comparados com trabalhos já publicados. 


\section{REFERÊNCIAS BIBLIOGRÁFICAS}

1. BANAT, I. M.; FRANZETTI, A.; GANDOLFI, I. BESTETTI, G.; MARTINOTTI, M. G.; FRACCHIA, L.; SMYTH T. J.. MARCHANT, R. Microbial biosurfactants production, applications and future potential. Applied Microbiology Biotechnoly, v. 87, p. 427-444, 2010.

2. BARROS NETO, B.; BRUNS, R. E.; SCARMINIO, I. S. Como fazer experimentos - Pesquisa e desenvolvimento na ciência e na indústria. 2 ed. Editora UNICAMP, Campinas, 2003.

3. BARROS, F. F. C.; PONEZI, A. N.; PASTORE, G. M. Production of biosurfactant by Bacillus subtilis LB5a on a pilot scale using cassava wastewater as substrate. J Ind Microbiology Biotechnology v. 35; p.1071-1078. 2008.

4. BATISTA, S. B.; MOUNTEER, A. H., AMORIM, F. R., TÓLOLA, M. R. Isolation and characterization of biosurfactant/bioemulsifier-producing bacteria from petroleum contamined sites. Bioresource Technology v.97, p.868-875, 2006.

5. BELLO, X. V.; DEVESA-REY, R., CRUZ, J. M.; MOLDES, A. B. Study of the Synergistic Effects of Salinity, $\mathrm{pH}$, and Temperature on the Surface-Active Properties of Biosurfactants Produced by Lactobacillus pentosus. Journal of Agricultural and Food Chemistry. v. 60, p. 1258-1265, 2012.

6. BENINCASA, M.; ABALOS, A.; OLIVEIRA, I.; MANRESA, A. Chemical structure, surface properties and biological activities of the biosurfactant produced by Pseudomonas aeruginosa LBI from soapstock. Antonie van Leeuwenhoek. v. 85, p. 1-8, 2004.

7. BEZERRA, M.S. Levantamento e Avaliação de Critérios para a Ampliação de Escala da Produção de Biossurfactante Utilizando Melaço como Substrato. 2006. 101f. Dissertação de mestrado, Universidade Federal do Rio Grande do Norte, Departamento de Engenharia Química, Natal/RN.

8. BICCA, F. C.; FLECK, L. C.; AYUB, M. A. Z. Production of biosurfactant by hydrocarbon degrading rhodococcus ruber and rhodococcus erythropolis. Revista de Microbiologia. V. 30, p. 231-236, 1999.

9. CALVO, C.; TOLEDO, F.L.; GONZÁLEZ-LÓPEZ, J. Surfactant activity of a naphthalene degrading Bacillus pumilus strain isolated from oil sludge. Journal of Biotechnology, v.109, p.255-262, 2004.

10. CAMEOTRA, S. S.; MAKKAR, R. S. Biosurfactant-enhanced bioremediation of hydrophobic pollutants. Pure Applied Chemistry. v. 82, p. 97-116, 2010.

11. COHEN, R.; TODOROV, R.; VLADIMIROV, G.; EXEROWA, D. Effect of Rhamnolipids on Pulmonary Surfactant Foam Films. Langmuir Article. v. 26, Issue 12, p. 9423-9428, 2010.

12. CORDEIRO, G. Q. Tratamento de Manipueira em Reator Anaeróbio Compartimentado Produção de Biossurfactante Utilizando Melaço como Substrato. 2006. 91f. Dissertação de mestrado, Universidade Estadual de São Paulo, Departamento de Engenharia e Ciência de Alimentos, São José do Rio Preto/SP.

13. COSTA, S. G. V. A. O.; · MILOT, F. L. S.; · DÉZIEL, E.; · NITSCHKE, M.; CONTIERO, J. Cassava wastewater as a substrate for the simultaneous production of rhamnolipids and 
polyhydroxyalkanoates by Pseudomonas aeruginosa. J. Ind Microbiology Biotechnology. v. 36, p. 1063-1072, 2009.

14. COSTA, S. G. V. A. O.; NITSCHKE, M.; CONTIERO, J. Produção de biotensoativo a partir de resíduos de óleos e gorduras. Ciência e tecnologia de alimentos, v. 28 (1), p. 34-38, 2008.

15. DAS, K.; MUKHERJEE, A. K; SEN, R. Improved bioavailability and biodegradation of a model polyaromatic hydrocarbon by a biosurfactant producing bacterium of marine origin. Chemosphere. V. 72, Issue 9, p. 1229-1234, 2008

16. DAS, K.; MUKHERJEE, A.K. Characterization of biochemical properties and biological activities of biosurfactants produced by Pseudomonas aeruginosa mucoid and non-mucoid strains isolated from hydrocarbon-contaminated soil sample. Applied Microbial Biotechnology, v.69, p.192-199, 2005.

17. FATHABAD, E. G.; Biosurfactants in pharmaceutical industry (a mini-review). American journal of drug discovery and development, v. 1, p. 58-69, 2011.

18. GOMES, M. Z. V.; NITSCHKE, M. Evaluation of rhamnolipid and surfactin to reduce the adhesion and remove biofilms of individual and mixed cultures of food pathogenic bacteria. Food Control. v. 25, Issue 2, p. 441-447, 2012.

19. HABA, E.; ESPUNY, M. J.; BUSQUETS, M.; MANRESA, A. Screening and production of rhamnolipids by Pseudomonas aeruginosa 47T2 NCIB 40044 from waste frying oils. Journal of Applied Microbiology. v. 88, p. 379-387, 2000.

20. KRONEMBERGER, F.A., SANTA ANNA, L. M. M., MENEZES, R. R., FERNANDES, A. C. L. B., BORGES, C. P., FREIRE, D. M. G. Controle da Oxigenação na Produção de Biossurfactantes em Biorreator, SINAFERM, Curitiba-PR, 2007.

21. LI, A.; Xu, M.; SUN, W.; SUN, G. Rhamnolipid Production by Pseudomonas Aeruginosa GIM 32 Using Different Substrates Including Molasses Distillery Wastewater. Applied Biochemistry Biotechnology. v. 163, p. 600-611, 2011.

22. LI, Q.; KANG, C.; WANG, H.; LIU, C.; ZHANG, C. Application of microbial enhanced oil recovery technique to Daquing Oilfield. Biochemical Engeneering Journal, v.11, p.197-199, 2002.

23. LOBATO, A. K. C. Estudo da produção de biossurfactantes por microrganismos isolados de poços de petróleo. 2003. 148f. Dissertação (mestrado) - Universidade Federal do Rio Grande do Norte, Departamento de Engenharia Química, Natal/RN.

24. LOURITH. N.; KANLAYAVATTANAKUL, M. Natural surfactants used in cosmetics: glycolipids. International Journal of Cosmetic Science. v. 31, p. 255-261, 2009.

25. LOVAGLIO, R. B.; DOS SANTOS, F. J.; JAFELICCI JUNIOR M.; CONTIERO, J. Rhamnolipid emulsifying activity and emulsion stability: $\mathrm{pH}$ rules. Colloids and Surfaces B: Biointerfaces. v. 85, p. 301-305, 2011.

26. MAKKAR, R. S., CAMEOTRA, S. S. An update on the use of unconventional substrates for biosurfactant production and their new applications. Appl. Microbial Biotechnol. v. 58, p. 428434, 2002. 
27. MAKKAR, R. S.; CAMEOTRA, S. S.; BANAT, I. M. Advances in utilization of renewable substrates for biosurfactant production. AMB Express, p. 1-5, 2011.

28. MOHAMMAD, A.; MAWGOUD, A.; LÉPINE, F.; DÉZIEL, E. Rhamnolipids: diversity of structures, microbial origins and roles. Applied Microbiology Biotechnology. v. 86, p.13231336, 2010.

29. MUKHERJEE, S.; DAS, P.; SEN, R. Towards commercial production of microbial surfactants. Trends in Biotechnology. v. 24, n.11, 2006.

30. NITSCHKE, M.; COSTA, S. G. V. A. O. Biosurfactants in food industry. Trends in Food Science \& Technology. v. 18, p.252-259, 2007.

31. NITSCHKE, M.; PASTORE, G. M. Biossurfactantes: propriedades e aplicações. Química Nova, v.25, n.5, p.772-776, 2002.

32. NITSCHKE, M.; PASTORE, G.M. Production and properties of a surfactant obtained from Bacillus subtilis grown on cassava wastewater. Bioresource Technology, v.97, p.336-341, 2006.

33. PACWA-PŁOCINICZAK, M.; PŁAZA, G. A.; PIOTROWSKA-SEGET, Z.; CAMEOTRA, S. S. Environmental Applications of Biosurfactants: Recent Advances. Int. J. Mol. Sci. v. 12, p. 633654; 2011.

34. Raza, Z. A.;, Khan, M. S.; Khalid, Z. M. Evaluation of distant carbon sources in biosurfactant production by a gamma ray-induced Pseudomonas putida mutant. Process Biochemistry. v. 42, p. 686-692, 2007.

35. SABATINI, D.A.; McINERNEY, M.J.; YOUSSEF, N.; NGUYEN, T. Evaluation of sub-micellar synthetic surfactants versus biosurfactants for enhanced LNAPL recovery. Final Report, p.1-57, 2006.

36. SANDRIN, T. R., CHECH, A. M., MAIER, R. M. A Rhamnolipid Biosurfactant Reduces Cadmium Toxicity during Naphthalene Biodegradation. Applied Environmental Microbiology. v. 66(10): p. 4585-4588. 2000.

37. SARAVANAKUMARI, P.; MANI, K. Structural characterization of a novel xylolipid biosurfactant from Lactococcus lactis and analysis of antibacterial activity against multi-drug resistant pathogens. v. 101, Issue 22, p. 8851-8854, 2010.

38. SEKHON, K. K.; KHANNA, S.; CAMEOTRA, S. S. Enhanced biosurfactant production through cloning of three genes and role of esterase in biosurfactant release. Microbial Cell Factories. v.10, p. 1-10, 2011.

39. SCHMIDELL, W.; LIMA, U. A.; AQUARONE, E.; et al. Biotecnologia Industrial. Engenharia bioquímica. São Paulo: Edgar Blucher,. v. 2, 2001.

40. SCHMIDELL, W.; LIMA, U. A. Biotecnologia industrial: engenharia bioquímica. São Paulo: Blucher, v. 4, 2007.

41. WEI Y. H.; CHOU C. L.; CHANG J. S. Rhamnolipid production by indigenous Pseudomonas aeruginosa J4 originating from petrochemical wastewater. Biochemical Engineering Journal v.27, p.146-154, 2005. 